\title{
Rita Levi Montalcini (1909-2012)
}

The Italian Society of Experimental Biology remembers with profound and heartfelt admiration Professor Rita Levi Montalcini, a great woman and scientist who left a decisive mark on the history of Experimental Biology. As an Honorary Member, she shared the aim of the Italian Society of Experimental Biology of fostering the training of young researchers. An attentive participant in the scientific activities of the Society, she delivered the opening lecture to the General Assembly in L'Aquila in 1979 "Spectrum of action of NGF in neurogenesis: from pluripotent effector to specific factor in the sympathetic neurone".

On the occasion of the Society's $75^{\text {th }}$ Anniversary held in Rome in December 2000, she chaired the Round Table "Problem of re-equilibrium between basic and applied research in Biology and Medicine".

With farsighted vision, she emphasized that studies in experimental biology have important practical implications. In her speech during the inauguration of the Academic Year of the Turin Polytechnic, she repeated (to quote her exact words) that "basic research and applied research complement each other in a process that increasingly becomes one, without any confusion of roles, the first being devoted to the generation of new knowledge and the second to its application".

With her passion for research, she was able to convey to young people not only her great culture but also her enthusiasm for knowledge and her hope for the future. In addition to her great qualities as a scientist, Rita Levi Montalcini should be remembered for her particular attention to the centrality of the value of human life. 